\title{
Second malignancies in Hodgkin's disease: a complication of certain forms of treatment*
}

\section{Summary and conclusions}

A total of 764 patients with Hodgkin's disease treated with radiotherapy (RT) or chemotherapy or both were reviewed 3-186 months (median 43 months) after initial treatment to assess the incidence of second malignancies. Incidences of solid tumours and acute non-lymphoblastic leukaemia (ANLL) were calculated by a life-table method and percentages of patients affected derived from lifetable plots.

Within 10 years after initial treatment the overall incidence of second solid tumours was $7 \cdot 3 \%$, and over a comparable period $2.4 \%$ of patients developed ANLL. Solid tumours occurred only in patients given RT with or without adjuvant chemotherapy, and ANLL occurred only after treatment with MOPP (mustine, vincristine, procarbazine, and prednisolone) or modified MOPP regimens. Neither solid tumours nor ANLL occurred in patients given ABVD (adriamycin, bleomycin, vinblastine, and dacarbazine).

The highest incidence of leukaemia (5.4\%) occurred after treatment with extensive RT plus MOPP; hence the benefits of this approach in Hodgkin's disease must be weighed against its carcinogenic potential.

\section{Introduction}

The development of a second malignancy, particularly acute non-lymphoblastic leukaemia (ANLL), is increasingly being recognised as a complication of Hodgkin's disease. Though the association may occur by chance, it may be closely related to the type of intensive treatment used. Direct evidence, however, is lacking. Advances in radiotherapy (RT) and chemotherapy have led to significantly increased survival, and for many patients cure, at almost any stage of Hodgkin's disease. Nevertheless, this has not been achieved without some degree of treatment-induced morbidity, acute and delayed toxicity of antineoplastic treatment occurring in a broad range of tissues. ${ }^{1}$ Because of evidence in man of a potential carcinogenic effect of chemotherapy attention has been directed to studying risk factors for the development of new cancers. After the report from the National Cancer Institute in $1972^{2}$ several studies confirmed that patients with Hodgkin's disease treated with extensive RT and intensive chemotherapy-namely, MOPP (mustine, vincristine, procarbazine, and prednisolone) and modified MOPP regimens-are at greatest risk of developing a second malignancy. ${ }^{3-5}$

We decided to assess the incidence of second malignancies in groups of patients treated in various ways and with different *Presented in part at the 15th annual meeting of the American Society of Clinical Oncology, New Orleans, Louisiana, 14-15 May 1979.

Istituto Nasionale Tumori, Milan, Italy

P VALAGUSSA, BS, consultant statistician

A SANTORO, MD, clinical assistant, division of clinical oncology

R KENDA, MD, clinical assistant, division of radiology

F FOSSATI BELLANI, MD, clinical assistant, division of clinical oncology

F FRANCHI, MD, assistant, division of pathology

A BANFI, MD, director, division of radiology

F RILKE, MD, director, division of pathology

G BONADONNA, MD, director, division of clinical oncology drug regimens. We reviewed patients at comparable times after treatment $(a)$ to determine the true incidence of second cancers, (b) to discover the risks associated with different modes of treatment and different classes of drugs, and (c) to define as accurately as possible the time relations between the onset of Hodgkin's disease and the development of a second malignancy.

\section{Patients and methods}

We studied 764 patients with Hodgkin's disease (676 adults, 88 children) who had been admitted consecutively to this institute during January 1965 to December 1976. Patients were referred for either primary diagnosis and treatment, reassessment of staging, or salvage treatment. A complete history of the disease, type of staging, and sequence of treatments were available in all cases. All patients were staged as described ${ }^{6}$ according to the Ann Arbor classification. All slides were reviewed by the pathology division and the diagnosis of Hodgkin's disease confirmed.

Initial treatment varied with the type of presentation and strategy in use at the time. Thus of the 764 patients, $394(52 \%)$ had been given RT initially $289(38 \%)$ RT plus chemotherapy, and $81(10 \%)$ chemotherapy (mostly combination chemotherapy) alone. For analysis, however, we grouped patients according to type, extent, and amount of treatment that had been given by the time of review (January 1979). Patients who relapsed after primary treatment had either been given further RT, started on drug regimens other than those initially administered, or prescribed combined-modality treatments.

Table I gives the composition of the treatment groups as in January 1979. A total of 236 patients $(31 \%$ ) remained in the RT group either because they had not relapsed after first irradiation or because further RT had been given at the time of treatment failure. Of the patients initially included in the group giver chemotherapy alone, only $36(5 \%)$ remained; the others had been given RT either alone or combined with further chemotherapy for treatment failure. Thus the largest group comprised 492 patients (64\%) who had received either $(a) \mathrm{RT}$ plus chemotherapy initially and never relapsed; (b) RT plus chemotherapy initially and, after relapse, either RT or chemotherapy or both; (c) RT initially and, after relapse, either chemotherapy alone or chemotherapy plus RT; or $(d)$ chemotherapy alone initially and, after relapse, either RT alone or RT plus chemotherapy.

Treatment modes-In all cases RT was given as high-energy irradiation. During the first years most patients with localised lymphoma were given involved-field, upper-mantle, or lower-mantle irradiation, subtotal or total nodal irradiation being reserved for stage III disease. Later subtotal or total nodal RT was extended to patients with stages I and II of the disease. Doses usually ranged from 3000 to 5500 rads. Ovet the years combination chemotherapy was utilised, given either alone or with RT, consisting almost entirely of MOPP, MABOP, and ABVD (table I). MOPP was administered as described. ${ }^{7}$ MABOP is a modified MOPP regimen in which adriamycin $\left(25 \mathrm{mg} / \mathrm{m}^{2}\right.$ intravenously on days 1 and 8$)$ and bleomycin $\left(30 \mathrm{mg} / \mathrm{m}^{2}\right.$ intravenously on days 1 and 8 ) are substituted for procarbazine. ${ }^{8}$ ABVD (adriamycin $25 \mathrm{mg} / \mathrm{m}^{2}$ bleomycin $10 \mathrm{mg} / \mathrm{m}^{2}$, vinblastine $6 \mathrm{mg} / \mathrm{m}^{2}$, and dacarbazine $375 \mathrm{mg} / \mathrm{m}^{2}$ ) was designed to treat MOPP failures ${ }^{8}$ and was injected intravenously every 15 days. Cycles of all these regimens were restarted on day 29, the dosage being adjusted in cases of myelosuppression. All other drug regimens -used in a small group of patients-included alkylating agents or procabazine or both; some of these patients had already been given MOPP and ABVD.

Statistical-We calculated the incidence of second malignancies from the date of initial treatment using the actuarial life-table method. Percentages of patients with solid tumours or ANLL at the different 
TABLE I-Composition of treatment groups (Fanuary 1979)

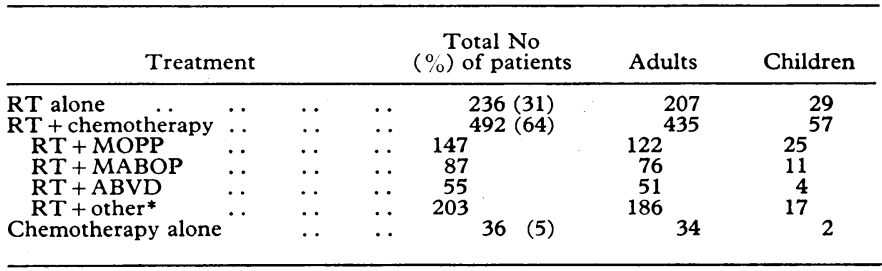

*Various combination or single-drug treatments containing alkylating agents or procarbazine or both

RT = Radiotherapy

MOPP $=$ Mustine, vincristine, procarbazine, and prednisolone.

MABOP $\mathrm{ABVD}=$ Adriamycin, bleomycin, vinblastine, and dacarbazine.

reported times were as derived from the life-table plots. The median time from initial treatment in the whole series was 43 months (range 3-186 months)

\section{Results}

Table II gives the incidences of second malignancy in patients treated with a single modality. The 236 patients given $\mathrm{RT}$ alone were reviewed after a median of 47 months (range 3-182 months). Involvedfield or mantle irradiation had been given to $119(51 \%)$ of these patients, subtotal nodal RT to $85(36 \%)$, and total nodal RT to $32(13 \%)$. None had developed ANLL within 10 years after initial treatment. During the same period, however, the incidence of solid tumours rose progressively to $14.9 \%$. Over one-third of the patients were reviewed five years or more after first irradiation.

The 36 patients treated with chemotherapy alone were reviewed after a median of 24 months (range 3-85 months). Thirty-two of them were given regimens containing alkylating agents or procarbazine or both. No solid tumours occurred in this group, but one patient (incidence $5.5 \%$ ) developed ANLL within three years after starting MABOP.

Of the 492 patients who received both RT and chemotherapy, $315(64 \%)$ were given subtotal or total nodal irradiation. The extent of the fields irradiated was comparable in the different groups. Except for patients given RT plus MABOP, there was no appreciable difference between the subgroups in the timing of review after initial treatment (median 44 months) (see table III). The subgroup given RT plus MABOP, however, were reviewed a median of 60 months after initial treatment, MABOP being the first combined drug regimen to be used systematically in our institute. The overall incidence of solid tumours in the 492 patients rose progressively to $6.2 \%$ within 10 years after initial treatment (table III). Such tumours, however, occurred only in subgroups given regimens containing an alkylating agent or procarbazine or both. The incidence of ANLL also increased with time (to $3.5 \%$ within 10 years) and again affected only patients treated with an alkylating agent or procarbazine. Of the patients given RT plus MOPP, for example, 5.4\% developed leukaemia within five years after initial treatment. In contrast, of patients reviewed at comparable times after RT plus ABVD, none developed either a solid tumour or leukaemia.

Table IV shows the initial treatments given to the nine patients who developed ANLL together with the timing of the diagnosis in relation to the beginning of initial treatment and the end of all treatment. Seven of the nine patients were given extensive radiotherapy plus combination chemotherapy. There was only one case of involved-field RT followed by prolonged administration of both mustine and procarbazine because of relapse. In five patients ANLL

TABLE IV-Initial treatment given to patients developing acute leukaemia

\begin{tabular}{|c|c|c|c|}
\hline \multirow[b]{2}{*}{ Treatment } & \multirow{2}{*}{$\begin{array}{c}\text { No of } \\
\text { patients }\end{array}$} & \multicolumn{2}{|c|}{ Time to diagnosis of leukaemia (months) } \\
\hline & & $\begin{array}{c}\text { After beginning } \\
\text { treatment }\end{array}$ & $\begin{array}{l}\text { After end of all } \\
\text { treatment }\end{array}$ \\
\hline $\begin{array}{l}\text { TNRT + MOPP } \\
\text { TNRT + MABOP } \\
\text { STNRT + MOPP } \\
\text { IFRT+HN2 + PCZ } \\
\text { MABOP .. .. }\end{array}$ & $\begin{array}{ll}\ldots & 3 \\
\because & 2 \\
\because & 2 \\
\because & 1 \\
\cdots & 1\end{array}$ & $\begin{array}{c}30,31,56 \\
32,65 \\
34,127 \\
102 \\
20\end{array}$ & $\begin{array}{c}18,5,22 \\
2,50 \\
23,27 \\
5 \\
4\end{array}$ \\
\hline
\end{tabular}

TNRT $=$ Total nodal radiotherapy.

STNRT = Subtotal nodal radiotherapy

IFRT + HN2 + PCZ = Involved-field radiotherapy plus mustine and procarbazine. Key to other treatment regimens given in table $\mathrm{r}$.

occurred within three years after beginning treatment, and in only one was leukaemia documented over 10 years after initial irradiation. In all nine cases leukaemia occurred while the patients were clinically in complete remission of their Hodgkin's disease, which in five cases had lasted over one year from the end of all treatment. This series included a child (aged 11 years) in whom Hodgkin's disease was initially treated with six cycles of MOPP followed by 12 months of maintenance treatment with procarbazine. Total nodal irradiation was administered because of relapse within three months after stopping procarbazine.

In all patients the onset of ANLL (myelomonocytic in five cases,

TABLE II-Incidences of second malignancy in Hodgkin's disease within 3, 5, and 10 years after treatment with either radiotherapy (RT) or chemotherapy alone. (Numbers of patients at risk given in parentheses)

\begin{tabular}{|c|c|c|c|c|c|c|c|c|c|}
\hline \multirow{2}{*}{\multicolumn{2}{|c|}{ Treatment }} & & & \multirow[b]{2}{*}{ No of patients } & \multirow{2}{*}{ Median time $\underset{\text { (months) }}{\text { after initial treatment }}$} & \multirow{2}{*}{$\begin{array}{l}\text { Second } \\
\text { malignancy }\end{array}$} & \multicolumn{3}{|c|}{ Percentage incidences } \\
\hline & & & & & & & $\begin{array}{l}\text { Within } \\
3 \text { years }\end{array}$ & $\begin{array}{l}\text { Within } \\
5 \text { years }\end{array}$ & $\begin{array}{l}\text { Within } \\
10 \text { years }\end{array}$ \\
\hline RT.. & .. & . & .. & 236 & 47 ; range $3-182$ & $\left\{\begin{array}{l}\text { Solid tumours } \\
\text { Leukaemia }\end{array}\right.$ & $\left.\begin{array}{r}1 \cdot 1 \\
0\end{array}\right\}(138)$ & $\left.\begin{array}{r}2 \cdot 6 \\
0\end{array}\right\}(84)$ & $\left.\begin{array}{r}14 \cdot 9 \\
0\end{array}\right\}(12)$ \\
\hline Chemotherapy & . & . & . & 36 & 24 ; range $3-85$ & $\left\{\begin{array}{l}\text { Solla tumours } \\
\text { Leukaemia }\end{array}\right.$ & $5 \cdot 5\}(11)$ & $5 \cdot 5\}(3)$ & \\
\hline
\end{tabular}

TABLE III-Incidences of second malignancy in Hodgkin's disease within 3, 5, and 10 years after treatment with radiotherapy (RT) plus chemotherapy. (Numbers of patients at risk given in parentheses)

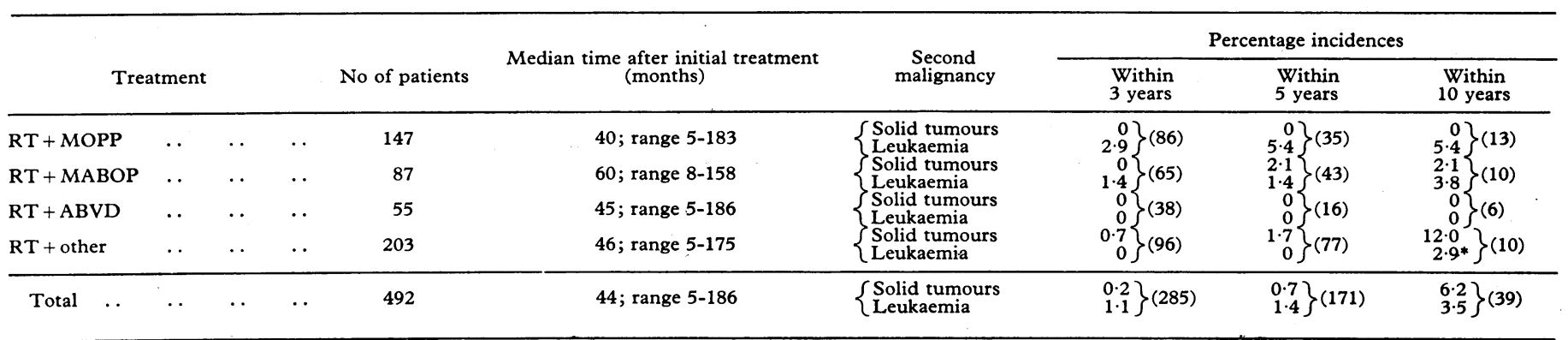


myeloblastic in four) was preceded by episodes of pancytopenia. All cytochemical studies were performed on specimens of peripheral blood and bone-marrow smears. Cytogenetic studies were not conducted. Eight of the nine patients died, the median survival after the diagnosis of ANLL being three months (range 1-11 months). The only patient alive at review had achieved complete marrow remission after treatment with androgens and corticosteroids in another hospital. In the other patients supportive and specific treatment including cytarabine, thioguanine, daunorubicin, and BCG had failed substantially to affect the course of leukaemia.

Table $\mathrm{V}$ lists the solid tumours that developed as a second malignancy. In one-third of the patients the tumours occurred in irradiated areas. Of all 15 patients with solid tumours, eight had been treated with RT plus chemotherapy-for example, three out of four patients who subsequently developed lung cancer had been given RT plus chemotherapy. In two of these patients the cancer occurred in irradiated areas. Patients who developed bronchial carcinoma were aged 40, 45, 51, and 63 years respectively. In a few cases solid tumours occurred within three years after initial treatment, and in one patient squamous-cell skin carcinoma was documented while he was still receiving chemotherapy for the underlying Hodgkin's disease. Almost all second solid tumours were confirmed histologically; of the three basal-cell carcinomas, however, two were diagnosed only clinically. The ages of patients with basal-cell skin carcinoma were 5, 40, and 80 years respectively. Eight of the 15 patients were alive at the time of review.

\section{Discussion}

The development of second malignancies in Hodgkin's disease was reported about 20 years ago, ${ }^{910}$ but the possible role of treatment in inducing acute leukaemia and solid tumours was recognised much later. In most recent reports second malignancies were diagnosed when the patients were in complete remission of Hodgkin's disease and off all treatment after receiving both intensive $R T$ and combination chemotherapy. A multifactorial aetiology has been postulated-namely, impaired cellular immunity characterising advanced Hodgkin's disease, immunosuppressive effects of intensive treatment, and direct cellular effects of radiation and chemotherapy. ${ }^{1311}$

In our series of 764 patients the development of solid tumours as a second disease occurred with an incidence of $7.3 \%$ within 10 years after initial treatment. Besides RT half of the patients had been given chemotherapy, which in all instances included an alkylating agent or procarbazine or both. Whether this heterologous group of tumours is related to treatment or represents a chance association, however, remains to be determined. Though therapeutic radiation may carry some increased risk of inducing a second tumour, ${ }^{12}$ in our series only five out of 15 patients (two out of seven given RT alone) had a second solid malignancy documented in an irradiated area.

The most serious delayed complication noted in our series was acute leukaemia. Leukaemia occurred irrespective of whether combined-modality treatment had been given initially (two cases) or whether either modality had been given only as salvage treatment (six cases). This finding agrees with the observations of the National Cancer Institute ${ }^{3}$ and Stanford ${ }^{4}$ groups. Our results leave little doubt that this complication is related to treatment. In the 492 patients treated with irradiation plus chemotherapy the incidence of leukaemia was $3.5 \%$ within 10 years after first treatment. Furthermore, 5.4\% of patients treated with RT and MOPP developed leukaemia within five years, whereas no cases of leukaemia were documented after RT given either alone or with ABVD.

The leukaemogenic potential in man of ionising radiation is well documented, ${ }^{11}$ and the incidence of post-irradiation leukaemia is known to be dose-related. So far as cytotoxic chemotherapy is concerned, many drugs have been incriminated in acute leukaemia, though alkylating agents predominate. ${ }^{111}$ All patients with documented acute leukaemia occurring in Hodgkin's disease had been given drugs containing an alkylating agent or procarbazine or both. ${ }^{13}$ Procarbazine is a most potent leukaemogenic compound in experimental animals. ${ }^{14}$ Although adriamycin and dacarbazine are carcinogenic in animals, ${ }^{15}{ }_{16}$ no cases of leukaemia or solid tumour occurred in our series after ABVD. Since patients given ABVD and other regimens were reviewed at comparable times after treatment we cannot explain the difference in carcinogenic effect between ABVD and combinations containing alkylating agents and procarbazine. Only relatively few patients were given ABVD, but we should have expected to find two patients with leukaemia from the number observed in the MOPP group. Hence, the drugs included in the ABVD regimen are probably weak carcinogens in man, at least when compared with alkylating agents and procarbazine.

How would recognising the risk of a second malignancy, particularly acute leukaemia, affect the treatment of Hodgkin's disease? Many patients with Hodgkin's disease are currently subjected to a combined-modality approach to improve the cure rate with extensive RT alone. From the 10-year results of the Stanford controlled trial ${ }^{17}$ (RT alone $v \mathrm{RT}$ followed by six cycles of MOPP) patients with stages I, II, and III of the disease apparently obtain improved rates of remission and survival as a result of adjuvant MOPP. ${ }^{18}$ Both $\mathrm{we}^{19}$ and the Yale group ${ }^{20}$ have shown that in advanced lymphoma (stages IIIA, IIIB, and IV) treated with combination chemotherapy followed by RT to sites of original disease $89-92 \%$ of complete responders were alive at five years, the results being superior to those usually obtained with MOPP chemotherapy alone. We do not infer that combined RT and chemotherapy should be regarded as an absolutely established method of treatment for all disease stages. Nevertheless, the combined-modality approach should clearly be tried further, at least in patients with unfavourable prognostic signs - for example, systemic symptoms, adenopathies above and below the diaphragm, and extranodal disease.

Since the results of this and other retrospective analyses show that extensive RT plus combination chemotherapy predisposes to the development of second malignancies, the benefit of such treatment must be weighed against its carcinogenic potential. Hence to reduce the risk of second malignancy possibly patients with disease confined to lymph nodes should be given RT alone as primary treatment, RT plus systemic chemotherapy being reserved for those who relapse. Patients who relapse after RT alone, however, are apparently at greater risk of developing acute leukaemia once chemotherapy has been given as salvage treatment. A second possibility would be to start combined

TABLE V-Details of solid tumours occurring as second malignancy.

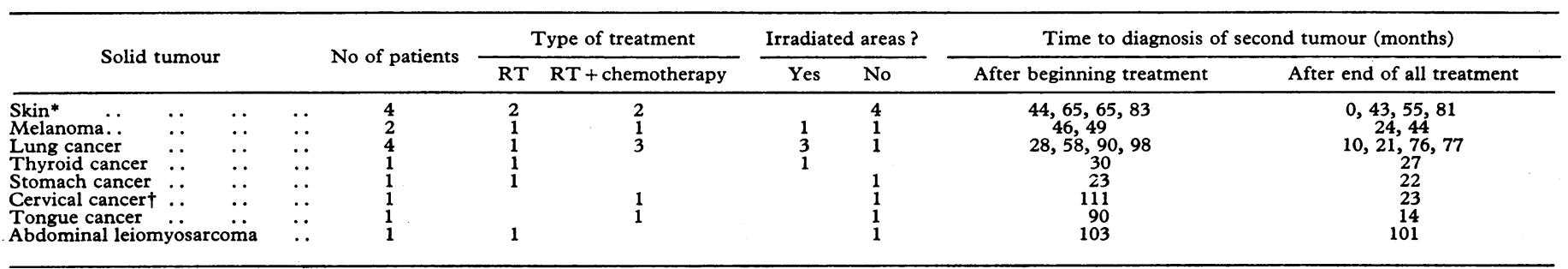


treatment in patients with an unfavourable prognosis but limit the cycles of chemotherapy. Initial results of the South-west Oncology Group suggest that in patients with stages IIB, IIIA, and $B$ of the disease three cycles of MOPP followed by total nodal RT yield excellent rates of remission and overall survival, which are comparable to those in patients given more than three cycles. ${ }^{21}$ Nevertheless, it is too soon to assess the difference in incidence of second malignancies between the two chemotherapy groups. Since second malignancies have occurred only in cases treated with alkylating agents or procarbazine, a third possibility would be to utilise ABVD chemotherapy for patients requiring a combined-treatment modality. From prospective controlled trials ${ }^{192}$ ABVD is apparently at least as effective as MOPP but devoid of carcinogenic activity.

Our results confirm that adults and children with Hodgkin's disease are especially susceptible to second malignancies, particularly acute leukaemia, when treatment includes extensive RT and combination chemotherapy with alkylating agents or procarbazine. Thus until more conclusive data from clinical trials have established the absolute therapeutic value of RT plus combination chemotherapy this form of treatment should be reserved for patients with an unfavourable prognosis. To avoid the risk of treatment-induced malignancies probably chemotherapeutic regimens not containing alkylating agents and procarbazine should be used.

Requests for reprints should be addressed to: Dr Gianni Bonadonna, Via Venezian, 1, 20133 Milan, Italy.

ADDENDUM-Since this paper was submitted three more adult patients have developed a second malignancy after RT plus chemotherapy. Essential data are as follows: Case 1-This patient initially received three cycles of MOPP plus total nodal irradiation. The histopathological diagnosis from a subcutaneous nodule removed 16 months after beginning treatment was diffuse histiocytic lymphoma. Case 2-This patient was initially treated with mantle irradiation. At the time of first recurrence he was given MOPP for 12 cycles, and ANLL was detected 66 months after beginning RT. Case 3-This patient was initially treated with subtotal nodal irradiation plus vinblastine. Subsequently she was given corticosteroids and procarbazine for a suspicious recurrence. A sarcoma of the anterior thoracic wall was detected 76 months after beginning irradiation.

\section{References}

${ }^{1}$ Sieber SM, Adamson RH. Toxicity of antineoplastic agents in man: chromosomal aberrations, antifertility effects, congenital malformations, and carcinogenic potential. Adv Cancer Res 1975;22:57-155.

2 Arseneau JC, Sponzo RW, Levin DL, et al. Non-lymphomatous malignant tumours complicating Hodgkin's disease: possible association with intensive therapy. $N$ Engl 7 Med 1972;287:1119-22.
${ }^{3}$ Canellos GP, De Vita VT, Arseneau JC, Whang-Peng J, Johnson REC. Second malignancies complicating Hodgkin's disease in remission. Lancet $1975 ;$ i: $: 947-9$.

${ }^{4}$ Coleman CN, Williams CJ, Flint A, Glatstein EJ, Rosenberg SA, Kaplan HS. Hematologic neoplasia in patients treated for Hodgkin's disease. $N$ Engl F Med 1977;297:1249-52.

5 Toland DM, Coltman CA, Moon TE. Second malignancies complicating Hodgkin's disease: the Southwest Oncology Group experience. Cancer Clin Trials 1978;1:27-33.

${ }^{6}$ Spinelli P, Beretta G, Bajetta E, et al. Laparoscopy and laparotomy combined with bone marrow biopsy in staging Hodgkin's disease. $\mathrm{Br}$ Med F 1975 ;iv :554-6.

${ }^{7}$ De Vita VT, Serpick AA, Carbone PP. Combination chemotherapy in the treatment of advanced Hodgkin's disease. Ann Intern Med $1970 ; 73: 881-95$.

${ }^{8}$ Bonadonna G, De Lena M, Monfardini S, et al. Combination usage of adriamycin in malignant lymphomas. Cancer Chemother Rep 1975;6: 381-8.

${ }^{9}$ Moertel CG, Hagerdorn AB. Leukemia or lymphoma and coexistent primary malignant lesions. A review of the literature and study of 120 cases. Blood 1957;12:788-803.

${ }^{10}$ Razis DV, Diamond HD, Craver LF. Hodgkin's disease associated with other malignant tumors and certain non-neoplastic diseases. $A m \mathcal{F}$ Med Sci $1959 ; 238: 327-35$.

11 Casciato DA, Scott JL. Acute leukemia following prolonged cytotoxic agent therapy. Medicine (Baltimore) 1979;59:32-47.

12 Seydel GH. The risk of tumor induction in man following medical irradiation for malignant neoplasm. Cancer 1975;35:1641-5.

13 Cadman EC, Capizzi RL, Bertino JR. Acute non-lymphocytic leukemia. A delayed complication of Hodgkin's disease therapy: analysis of 109 cases. Cancer 1977;40:1280-96.

14 O'Gara RW, Adamson RH, Kelly MG, Dalgard DW. Neoplasms of the hematopoietic system in non-human primates: report of one spontaneous tumor and two leukemias induced by procarbazine. $\mathcal{F}$ Natl Cancer Inst $1971 ; 46: 1121-30$.

15 Weisburger JH, Griswold DP, Prejean JD, Casey AE, Wood HB, Weisburger EK. The carcinogenic properties of some of the principal drugs used in clinical cancer chemotherapy. Recent Results Cancer Res $1975 ; 52: 1-17$.

${ }^{16}$ Schmähl D, Habs M. Experimental carcinogenesis of antitumour drugs. Cancer Treat Rev 1978;5:175-84.

17 Rosenberg SA, Kaplan HS, Glatstein EJ, Portlock CS. Combined modality therapy of Hodgkin's disease. A report on the Stanford trials. Cancer 1978;42:991-1000.

${ }^{18}$ Rosenberg SA, Kaplan HS, Brown BW. The role of adjuvant MOPP in the therapy of Hodgkin's disease: an analysis after ten years. In: Salmon SE, Jones SE, eds. Adjuvant therapy of cancer II. New York: Grune and Stratton (in press).

19 Bonadonna G, Santoro A, Zucali R, Valagussa P. Improved five-year survival in advanced Hodgkin's disease by combined modality approach. Cancer Clin Trials 1979;2:217-26.

${ }^{20}$ Prosnitz LR, Farber LR, Fischer JJ, Bertino JR, Fischer DB. Long-term remission with combined modality therapy for advanced Hodgkin's disease. Cancer 1976;37:2826-33.

${ }^{21}$ Coltman CA, Hall W, Montague E, Moon TE. Chemotherapy (MOPP) and total nodal radiotherapy (TNRT) in pathological stage IIB, IIIA and B Hodgkin's disease. In: Salmon SE, Jones SE, eds. Adjuvant therapy of cancer. Amsterdam: North Holland, 1977:529-36.

${ }^{22}$ Santoro A, Zucali R, Bonfante V, Volterrani F, Bajetta E, Bonadonna G. Comparative therapeutic effects and morbidity of two combined treatment modalities in PS IIB-III (A + B) Hodgkin's disease. Proc Am Soc Clin Oncol 1979;20:359 (abstr C-284).

(Accepted 23 October 1979)
ONE HUNDRED YEARS AGO The following story has recently reached the Statesman. "Dr Dumbleton, a young surgeon from St Bartholomew's Hospital, who only arrived in India to join the Indian Medical Service last March, was recently ordered to proceed to Peshawur. From Peshawur, Dr Dumbleton proceeded in medical charge of a draught en route to join the Kuram Valley force. Being but an indifferent horseman, he was much galled by his long ride. In addition, he suffered from a severe attack of fever, and, when on the march, his detachment met the 13th Bengal Lancers. The medical officer in charge of that regiment told Dr Dumbleton that he was in an utterly unfit state of health to proceed; he also provided him with a pair of drawers. Thus relieved, poor Dr Dumbleton managed to push on to Ali Kheyl. Here he went to a staff officer, who saw from his miserable appearance that he was quite unfit to go further, and he said that he would make arrangements for some other surgeon to go on with the detachment. The poor lad went to his tent, threw himself down in his clothes, and fell asleep. Early next morning, an officer of his detachment went to his tent and said, 'Come, Dumbleton, it is time to get up; we must be off.' Dr Dumbleton replied that he was utterly unfit to go on, as he was so ill, and that arrangements had been made for another surgeon to take his place; and the officer left him. Dr Dumbleton appears to have been a very sensitive young fellow, and he feared he should be accused of pretending to be worse than he really was. After a short time, the officer of his detachment returned, saying that no arrangement had been made for another surgeon to go with them, that they could not march without one, and that go he must. Dr Dumbleton replied that he could go no further, adding, 'By God, I am not shamming'; and the officer again left Dr Dumbleton in his tent. He had only gone a few yards when he heard the report of a pistol, and, rushing back to Dr Dumbleton's tent, he found the poor young fellow dead, with a revolver beside him." (British Medical fournal, 1880.) 